http://dx.doi.org/10.19183/how.24.2.341

\title{
Identity Construction and Reversal Conceptual Transfer Among Iranian EFL Learners
}

\section{Construcción de identidad y transferencia conceptual inversa entre estudiantes iraníes de inglés como lengua extranjera*}

\author{
Razieh Gholaminejad \\ Shahid Beheshti University, Tehran, Iran \\ R_Gholaminejad@sbu.ac.ir
}

This article draws on a qualitative study which seeks to explore whether Iranian English as a foreign language learners experience any reversal conceptual transfer and whether they construct two identities as a result of learning a foreign language. The findings from the open-ended questionnaires distributed among 65 undergraduates at the University of Isfahan as well as 45 interviews conducted in a private language school reveal that most of the participants feel they have partly experienced reversal conceptual transfer. However, most of them claimed not to have constructed a new foreign language identity in English, while those who did had a more positive attitude towards their English identity.

Key words: English as a foreign language, identity, reversal conceptual transfer, Whorfian linguistic relativity.

El presente artículo describe un estudio cualitativo para identificar si estudiantes iraníes de inglés como lengua extranjera experimentan transferencia conceptual inversa y si construyen dos identidades como resultado del aprendizaje de una lengua extranjera. Los resultados de cuestionarios abiertos distribuidos entre 65 estudiantes de pregrado de la Universidad de Isfahan y de 45 entrevistas realiza-

Received: December 18, 2016. Accepted: May 13, 2017.

How to cite this article (APA 6th ed.):

Gholaminejad, R. (2017). Identity construction and reversal conceptual transfer among Iranian EFL learners. HOW, 24(2), 63-79. http://dx.doi.org/10.19183/how.24.2.341.

This article is licensed under a Creative Commons Attribution-NonCommercial-NoDerivatives 4.0 International License. License Deed can be consulted at http://creativecommons.org/licenses/by-nc-nd/4.0/. 
das en una escuela privada revelaron que la mayoría de los participantes sienten que han parcialmente experimentado transferencia conceptual inversa. Sin embargo, la mayoría afirmó no haber construido una nueva identidad en inglés, pero los que sí lo hicieron tienen una actitud más positiva hacia su identidad en inglés.

Palabras clave: identidad, inglés como lengua extranjera, principio de relatividad lingüística, transferencia conceptual inversa

\section{Introduction}

Regardless of which language they speak, people are not just involved in the act of information exchange while speaking; they are continually constructing a sense of who they are. To put it another way, people negotiate their identities while speaking (Norton, 1997). Language is not only a tool for communication, but is also interrelated to a set of behavioral norms and cultural values which construct one's identity (Gao, Cheng, Zhao, \& Zhou, 2005).

According to Joseph (2004), identity is more than a by-product of linguistic communication. It is to a great extent established and sustained by language (Gumperz \& Cook-Gumperz, 1982). Language is the mix, result, and outcome of the internal and external interpretations of identity (Gibson, 2004).

The language people speak is constructed by their identity and their identity is formed by the language they speak. But what makes a serious problem here is that prolonged contact with a foreign language (L2) and being immersed in "a new and different cultural setting causes irremediable destabilization of the individual's sense of self" (Block, 2002, p. 4). Besides, perceiving the spread of English as a manifestation of "linguistic imperialism", some researchers (e.g., Skutnabb-Kangas, 2000) maintain that, as a primary tool for globalization, "English plays an invasive and aggressive role that conflicts with the linguistic and cultural integrity of other nations" (Gu, 2009, p. 140). Globalization and technological development have increased the potential for the creation of dual and hybrid identities (Block, 2008; Caldas-Coulthard \& Iedema, 2008; Kanno, 2003), which have led to difficulties in categorizing people in groups such as class, race, and gender. This has brought about a growing sense of ambiguity towards one's sense of self (Miyahara, 2010).

Ryan (2006) notes that "whether the culture accompanying the language of globalization subtracts from or adds to the individual's existing cultural identity is crucial in determining learner willingness or unwillingness to acquire that culture's language" (p. 31). According to Shardkova and Pavlenko (2004), English learners undergo significant identity conflicts when they speak English. Similarly, studies conducted by Bashir-Ali (2006) and Norton (1997) demonstrate that some English learners, in the process of assimilation, feel the need to deny their L1 cultures to assimilate into the mainstream English academic discourse. Learning an 
L2 in an English as a second language (ESL) context, beyond acquiring linguistic aspects, involves a process of acculturation. A closely related phenomenon, as a result of acculturation, is identity formation. When human beings try to understand themselves in the process of their growth, they create layers of defenses to protect their egos (Brown, 2005). Since second language acquisition (SLA) and acculturation occur simultaneously, the inevitable changes give rise to a self-protective mechanism in the ego. The language ego sticks to the L1 to protect itself neophobically. Thus, language interacts with ego development (Brown, 2005). The fear of losing one's worldview or identity because of learning English is not a simple matter; it may produce resistance to the norms of the new context (Ige, 2007; Sterling, 2000). In an ESL context, prolonged contact with an L2 and being immersed in a new cultural setting causes irremediable destabilization and ambivalence of the L2 learner's sense of self (Block, 2002), leading to the creation of dual and hybrid identities (Block, 2008).

When people travel to live in an environment where the norms and values are different from their own, it is expected that they appropriate the predominant norms and values in order to be integrated into the new setting and to improve their ability to communicate with others (Block, 2007; Wenger, 1998). This requires changes in the individuals' perceptions, values, and worldviews (Brown, 2005).

According to linguistic relativity, not all ideas can be uttered perfectly in all languages; the language we speak implicitly indicates the meanings that we can express. Besides, through L2 learning, we learn some cultural concepts as well as thought patterns. It is the grammatical patterns of a language which we learn that influence the thought patterns that we develop, which subsequently affect our behavior (Hudson, 1996). Closely related to Whorfian linguistic relativity is conceptual transfer (Ellis, 2007), which in one way is summed up as "the way people view the world is determined wholly or partly by the structure of their native language" (p. 377). In other words, the underlying ways in which we perceive and conceptualize the world around us are affected by our L1; our L1s have made us glasses to look at the world for the rest of our lives.

The conceptual transfer, and the fact that our L1s provide us with glasses to look at the world, can raise the question of whether the L2 learners' worldview and ideology can change or at least be affected by learning a second or foreign language — a phenomenon that I called reversal conceptual transfer (RCT). According to RCT, in the process of L2 acquisition, a learner progressively looks at the world through a new perspective, which gives him or her a larger image of the cultural assumptions related to the L2. This modifies or at least affects the L2 learners' meaning schemas (Mezirow, 1991). This phenomenon can be considered as an integral part of identity formation since the pre-requirement for the construction of a new identity would be the construction of a new set of world views and beliefs. RCT assumes that as a result of L2 learning and exposure to a new set of cultural perspectives and ideologies, 
the L2 learners will be gradually, inevitably, and subconsciously affected, and then they may be inclined to develop new identities.

In the last ten years, research concerning the relationship between language and identity has experienced an extraordinary development. However, minimal research has been done on the issue of identity change among Iranian English as a foreign language (EFL) learners, specifically. Iran, where strong religious and cultural identities have been preserved since the Islamic revolution, seems an untouched location for a study on the impact of L2 learning on learners' identities and occurrence of RCT. The current society of Iran has been strongly ruled by the Islamic doctrine, which views religious principles as the best way of life (Mokhtarnia, 2011). English is only a school subject in Iran, and is taught as a foreign language, rather than as a second or additional one. Students usually consider it just another course like geography, history, and so forth, as it is not supposed to be used as a language of everyday communication.

This study, which was a part of a broader project, aimed to explore three questions: Do Iranian EFL learners experience RCT? Do they construct a second identity because of learning English? If yes, then, how different are these two identities? Following a qualitative approach, open-ended questionnaires and interviews were conducted to explore these questions.

\section{Theoretical Framework}

\section{Identity and Language}

A person's identity, put as simply as possible, has two basic aspects: their names, which make them distinguished from others, and "that deeper, intangible something that constitutes who one really is", referred to as "soul", "ego", or "self" (Joseph, 2004, p. 1). This "self" or identity has many dimensions: cultural, ethnic, social, personal, and so on, among which there is interplay. According to $\mathrm{Wu}$ (2011), while the individual's use of language reflects an expression of personal identity, it is always in relation to a broader social context. That is, it consists of both who we think ourselves to be and how we wish others to perceive us.

As Riley (2006) notes, identity is a tricky and complex term. While pointing to the differences that make us distinct from one another, it also refers to the similarities that we share with others. It is "multiple" in the sense that an Iranian woman, for instance, can view herself as a Persian speaker, a mother, a swimmer, and an accountant depending on different contexts. It is "conflicting" in the sense that a doting mother can at the same time be a stern boss. Finally, it is "dynamic" in the sense that a previous thief can stop stealing (Weedon, 1997). People shift among their multiple identities while playing different roles in different 
groups (Wu, 2011) and define themselves continually based on the activated dimension of identity. The more often a role is practiced within a certain social boundary, the more deeply that dimension of identity will be formed (Block, 2007). In line with constructivism (Miyahara, 2010) identities, hence, are not containers into which we are poured; rather, one assumes an identity and then works on it to shape it (Mathews, 2000). This is contrary to the traditional perspective where it is contended that we are provided with the narrative and social role, rather than being able to create one ourselves.

As language comprises a combination of behavioral norms and cultural values, each utterance we make is an act of identity (Le Page \& Tabouret-Keller, 1985). In other words, while speaking, we are subconsciously constructing and reconstructing a sense of who we are (Norton, 1997). Framed in a mutual relationship, identity is formed by the language we speak, and uses language as an instrument for symbolizing itself and making its presence realized.

If people become conscious of the dynamic process and multiple identities within them, they can also "play" with their languages and identities, deliberately shifting from one language/variety to another, thereby signalling a change from one identity to another (Byram, 2006).

The interest in the relation between identity and L2 learning, although only marginally explored in the SLA field (Menard-Warwick, 2005), goes back to the late 1980s (Norton, 2008). In recent decades and especially over the past decade, however, it has become increasingly recognized (Belz, 2002; Block, 2007; Burck, 2011; Chik \& Benson, 2008; Gao, Zhao, Cheng, \& Zhou, 2007; Kanno, 2003; Mills, 2001; Norton \& Toohey, 2001; Pavlenko \& Blackedge, 2003; Toohey, 2000). The findings demonstrate that "people experience life and themselves differently when they speak different languages" (Burck, 2011, p. 365). This happens especially when the languages involved have substantial differences, such as English and Chinese, where a Chinese person may be able to better express his aggressiveness in English (Pavlenko, 2006).

The way identities are affected by L2 learning can be different depending on whether the L2 is learned in an ESL or EFL context. Since this study was carried out in an EFL setting, this is explained in detail in the following section.

L2 identity formation in the EFL context. Most studies on the interaction between identity and L2 learning attempt to explore the experiences of immigrant learners in host countries where English represents a dominant means of communication (Belz, 2002; Kanno, 2003; Norton \& Toohey, 2001; Pavlenko, 2001, 2003). However, relatively few studies have been conducted of EFL learners' identity construction in their homeland contexts where L1 not L2 is the dominant means of communication, where there is no chance of immersion and the only source of exposure to L2 is the educational setting. The findings from the ESL 
contexts do not seem unanticipated, considering the geographical movement and the societal and psychological changes of the learners. Yet, in the case of EFL, the immediate classroom context and the surrounding educational culture are the only sources of exposure (Block, 2007).

While research has indicated that in real life $\mathrm{L} 2$ learner identity construction is a complex interplay of various variables (Kim, 2003), in the classroom, as Zacharias (2010) notes, there are two prominent factors affecting learner identity construction: teaching approaches and textbooks. Many researchers (e.g., Byram, 2006) believe that both natural acquisition and formal teaching can create, strengthen, or weaken the relationship between languages and identities. Kramsch (1993) explains that identities are not fixed constructs that EFL students bring to the classroom and then take away with no change having occurred at the end of a lesson or course. Similarly, Gao, Li, and Li (2002) studied the development of three college learners' identities in China, arguing that EFL learning can be an integral part of students' identity construction. Others believe that in EFL contexts, the L2 does not cause an identity conflict as harsh as in the ESL one; it still gives learners new viewpoints on their own society and culture and an opportunity to critically examine it (Gao, 2008; Pishghadam \& Sadeghi, 2011).

"Imagination" was mentioned by Norton $(2001,2006)$ as an important factor with which EFL learners view themselves as members of the community they desire (Wenger, 1998), leading to the creation of new identities which do have psychological reality (Gao, 2010).

\section{Method}

As untouched issues such as "identity" can best be examined through appropriating an ethnographic framework, a qualitative approach was used for this study. First, two classes consisting of $65 \mathrm{EFL}$ undergraduates who were all English non-native speakers were chosen based on convenience sampling in Isfahan University. Then they were administered openended questionnaires adapted from Jabur (2008) (see the Appendix). They were given enough time to write their answers to the questionnaire. In the second phase, which was mainly conducted as a triangulation, 45 graduates of a private language school were asked the questions of the questionnaire orally in the form of semi-structured interviews. It needs to be clarified that in order to explore the extent to which Omani Muslim women's identities were affected by writing in Enlish as a second language, Jabur used two qualitative methods: open-ended questionnaires as well as individual in-depth interviews. The methodology framework was also based on Jabur.

The results obtained from the questionnaires and interviews were analyzed using a coding process. Coding is one of the considerable ways used in data analysis in order to sort out, organize, and make sense of raw textual data, condensing it into categories or themes 
based on interpretation. Coding involves the creation of labels that are the synopses of the text being examined. For coding the data, one needs to combine it, looking for ideas. In order to do that, similar passages of the text need to be marked through a label, in a way that they can easily be searched and found at a later stage to make comparisons with and to identify any patterns that require further investigation (Taylor \& Gibbs, 2010). Since it is the research questions that suggest what pieces of the gleaned data need to be coded and what to be eliminated, the researcher first went through the data looking for things relevant to answering the research questions. Before coding, the textual data were closely read. Since there were no theories available, I generated categories inductively from the data. While I was coding the data, I had to make new codes, so once again I went back and checked the whole data. Then, some general headings, or labels that could best describe the related pieces of data were written. To label the codes, I used words and sentences from the literature review, and the research questions. These categories were selected in line with their significance or relevance to the research questions.

Then I read the data once more and identified some themes from the data that did not quite fit the codes already existing, so I made new codes. In other words, when I could not find an appropriate code, that is, when the text did not fit with the definitions, then I made new codes. I tried to code the data with skepticism and sensitivity, although data analysis in a qualitative research is co-creating an idea rather than discovering one.

Then, another copy of the coded data was made so that the sections I had labeled on my transcripts could be cut out. The coded data were sorted into groups according to topics. All of the pieces of data that had the same labels or closely related labels were put in the same group. Each group was labeled with a word or phrase that could refer to the gist of what was included in the group.

I made sure that everything in each group was related to the label given and then considered whether some groups could be combined. As a result, I deleted some of the groups which were insignificant. Subsequently, the analysis was written after organizing the groups in a proper order, connecting different pieces together. For doing so, I organized my themes, which took a while, striving to avoid ending the long process of coding with merely a collection of themes. After coding the data, I categorized and grouped the codes around themes and matched the questions with the identified themes. Finally, I sorted them into order, using a hierarchy.

Profile of participants. The participants' L1s were all Persian except three (a Lori, ${ }^{1}$ a Turkish, and an Armenian). They were all Muslims except one who was Christian. Only 19 participants had the experience of living abroad and learning English as an ESL.

A minor dialect used in some parts of Iran. 


\section{Results}

\section{Did the Participants Ever Experience RCT?}

The responses to the question were divided into two main groups. The first group, consisting of 35 out of 110 participants, believed that they have never learned new beliefs, ideas, meanings, and more about other or certain culture/s during the period of learning English, or in other words, they have never experienced RCT, even partly. This group's responses were analyzed as follows: Some of them hoped to experience this phenomenon in the future as they improve their English proficiency. Some others believed that the question was false by its very nature, explaining that humans' worldview has nothing to do with the language they learn. They explained that experiencing RCT can be assigned to other factors. Factors such as (1) the type of one's upbringing, (2) the fickleness or decisiveness of one's personality, (3) the amount of daily communication and exposure to English, (4) the age of starting to learn English (the younger, the more affected), and most importantly, (5) the experience of living abroad (and learning English in an ESL rather than EFL context) can contribute to the creation of RCT. Regarding the latter, a participant explained that her worldview changed only because she had spent her teen years away from her homeland, rather than simply as a result of learning English. She highlighted the key role of society to shape one's conducts. Besides, human agency was mentioned as a major factor, in a sense that an individual can decide to change his or her world view intentionally. Furthermore, appropriating a fundamentalist position, a few participants stated that a Muslim remains unaffected in terms of ideological perspective, if he or she has a firm belief in Islamic doctrine. Others assigned their lack of experience of this phenomenon to the fact that the English books and movies available to Iranians are primarily censored and the concept of culture is addressed in a very limited manner. As Mokhtarnia (2011) put it, in Iran the English materials are modified in terms of cultural contents to eliminate any expression, word, or image incongruous with Iranian culture or incompatible with Islam.

On the other hand, the second group, comprising 75 out of 110 participants, claimed that they partly experienced RCT. Some of them clarified their experience of this phenomenon by comparing their current state as opposed to before learning English. The following are examples of the RCT they had experienced: Some of them said that as a result of learning English, they experienced a gradual deepening of judgment that helped them look at things in a more open-minded way. They attributed this to the enhanced amount of thinking about differences between the L1 and L2 cultures. Others mentioned that they tended to respect and accept incongruent opinions, and started to become more flexible and liberal about different issues, especially freedom of women, speech, and boy and girl relationships. There were also participants who claimed to look at the world in a more self-centered and individualistic way, that is, giving priority to one's own interests and goals to those of others 
and adopting a more hedonistic style of living as a result of learning English. While some students said that by learning English, they had started to feel more embarrassed because of Iran's current underdevelopment, there were students who believed that they became more pessimistic about Western life. This can be attributed to the fact that most of them learned many aspects of Western culture based on commercial Hollywood movies (aimed to show any unreal exaggerated subjects including scenes that violate many Islamic values) rather than real Western life. Finally, there were participants who claimed to have started reconsidering the Islamic principles and Iranian culture in a different way, by learning English. This is in line with Pishghadam and Sadeghi (2011), who noted that EFL learning gives learners an opportunity to examine critically their home culture. Many participants explained that because of comparing Western ideology and culture as a by-product of learning English with those of their own, they realized how rich and constructive the Islamic culture is, and increasingly felt proud of being a Muslim, making them more certain about the perfection of the Islamic teachings. For example, secularism and materialism, and the resultant nihilism or using women's bodies to satisfy men's desires, which prevails in Western culture, is condemned in Islamic culture, and the participants said that they are proud of this because of its underlying logic.

Interestingly, all participants who already had the experience of living abroad claimed to have experienced RCT because of learning English, which makes it plausible to suggest that immersion in an ESL context plays a central role in experiencing RCT. This verified Block (2007), who considers such findings from L2 learners in ESL contexts quite anticipated, taking into account the geographical movement and societal change of the communities of practice in which they participate.

\section{Have the Participants Ever Constructed a New Identity?}

Surprised by the nature of the question, most of the participants (91 out of 110) stated that learning English had nothing to do with the formation of a new identity, as English was nothing but a school subject or major. They reported that they are not someone else while communicating in English and that L1 and L2 are only two means of describing one person. These participants, labeled as "those answering negatively", explained that hardly ever can any Iranian EFL learner pretend to have two identities because their experiences of the two languages are not identical; while Persian is spoken in all domains of an Iranian's life, and one is normally raised from birth to death in this society, English is only limited to the classroom. So, due to the inequality of the exposure to the two languages, one cannot have two distinct equal identities for each language and cannot claim to feel closer to his or her L2 identity. Even in the limited time spent in school contexts, English is rarely used communicatively to contribute to students' creation of new identities, as the Iranian educational system for teaching English uses a type of grammar-translation method which requires students to 
memorize lists of words, focus on the grammar, and translate texts into Persian. Besides, some participants assigned the phenomenon of having dual identities to lack of stability in one's character - a negative feature. Others, showing a patriotic orientation, claimed to be proud of having only one identity—the Muslim one.

In contrast, the second group, which included a few participants (19 out of 110), considered themselves to have new L2 identities while communicating in English, although they regarded their L2 identities as a complement to their L1 identities, rather than being in conflict with it. This confirms Jabur's (2008) study, which concluded the same results. One of the participants explained that whenever she starts describing herself in Persian, the description goes on rather different from when she does it in English. This makes her believe that she has constructed two distinct identities. Interestingly, all of the three participants whose L1s were other than Persian (i.e., a Lori, a Turkish, and an Armenian) ${ }^{2}$ claimed to have more than one identity. The Lori and Turkish one (both of whom were Muslims, though had non-Persian L1s) claimed to have two identities. But, the Armenian participant (who also had a non-Persian L1, but whose religion was Christian), as the only case of a religious minority in the sample, pointed out that he sometimes feels he has even three identities: an Iranian, a Christian, and an English one. Since among these three participants, only the Armenian one claimed to have three identities, whereas the other two stated that they had two identities, it may be fair to conclude that religion may play a significant role in identity formation of the language learners.

It should also be noted that most of the participants who claimed to have two identities had already experienced living abroad. This leads us to the following view: learning English as a second rather than a foreign language does make a new identity for the language learner. Perhaps this is due to the context in which the language is learned. One could argue that there is much more pressure to communicate in an environment where the language that is being learned is also an official one. This confirms other studies conducted in an ESL context (e.g., Belz, 2002; Kanno, 2003; Norton \& Toohey, 2001; Pavlenko, 2001, 2003).

Those who felt two (or more) identities were asked to differentiate between the selfimage of their different identities. They tended to favor their English identity by using more positive words to describe themselves. They considered their English identity to be more flexible, attractive, disciplined, ebullient, excited, optimistic, garrulous, self-confident, frank, and assertive. Many of them also mentioned that their English self is able to reject people's requests, is more individualistic and liberal, who devalues the role of family, while others believed it to be more secular, unrestrained, and easygoing in terms of sexual relationships, God, and so on.

In Iran, people who speak Lori and Turkish are typically Muslims, and those who speak Armenian are Christians. 
As most of the participants failed to construct a second identity, it seems fair to conclude that the Islamic fundamentalist ideology among Iranian English-major students, which inspires them to reject non-local culture, is actively working. Furthermore, the strategies undertaken by the government against cultural invasion and linguistic imperialism, such as censoring the cultural aspects of the Western daily lifestyle from textbooks and adding Islamic values to them, seem to be proceeding quite successfully.

\section{Conclusion}

From the findings of this study, invaluable conclusions were drawn:

The first conclusion is that most of the participants experienced RCT while learning EFL in the following ways:

1. Deepening of judgment through developing an open-minded view.

2. Respecting and accepting incongruent opinions, developing more tolerance, flexibility, and liberality.

3. Looking at the world in a more individualistic and hedonistic way.

4. Feeling more embarrassed because of Iran's current underdevelopment, when compared to the West.

5. Reconsidering the Islamic principles and Iranian culture and critically analyzing values and devalues.

6. Becoming more pessimistic about Western life.

7. Becoming more optimistic about local life, and feeling proud of being a Muslim.

Since those who already had the experience of living abroad claimed to have experienced RCT, it is plausible to suggest that immersion in an ESL context plays a central role in experiencing RCT. Besides, since some of the participants, instead of being attracted to the Western culture, continued to be attached to their own local culture, while others tended to critically analyze what was previously taken for granted as good or bad, values or devalues, one may conclude that both appreciation and depreciation of the cultural values (Pishghadam \& Sadeghi, 2011) have occurred.

The second conclusion is that for most of the participants, L1 and L2 were only considered two means of describing one person, and so hardly ever were two identities felt. Due to the inequality of the exposure to the two languages as well as adopting a grammarbased translation approach — rather than a communicative one-to English learning in the Iranian education system, one cannot develop distinct identities for each language. Having 
a negative attitude toward the phenomenon of duality of identities, as a sign of lack of stability in one's character or lack of patriotism, were also other factors preventing the participants from developing two identities. However, a few participants claimed to have new L2 identities, although they regarded their L2 identities as complements to their L1 identities, rather than in being in conflict with them. Interestingly, the participants (1) whose L1s were other than Persian, (2) whose religions were other than Islam, and (3) who had an experience of living abroad formed this group. Thus, having minority religions or languages in a society or having the experience of living abroad may play a significant role in identity formation. The third conclusion was that those who felt they had two (or more) identities tended to favor their English identity by using more positive words to describe themselves.

This confirms Abdollahzadeh and Baniasad (2010) who indicate that the hegemony of the English world is implicitly infused into the minds of the Iranian English learners through, among other things, the imported English textbooks. The image of the United States presented in the international books used to teach English in Iran is in the form of an ideal society, without any suggestion of that society's negative sides (Lummis as cited in Abdollahzadeh \& Baniasad, 2010).

As this study can be considered as a replication of Jabur (2008), it needs to be noted that the results did not confirm the findings of her research, in which English provided the participants with developing new identities among Omanis. Likewise, in Gu's (2009) study, conducted in an EFL Chinese context, the results did not turn out to be congruent with the present study. That is, unlike this study, for Gu's participants, English learning is a process of understanding who the learners are.

All in all, previous research conducted in EFL contexts indicated that English-major students mostly experience new identity formation. The present study, however, indicates that most of the Iranian English-major students do not experience any identity formation; they simply look at English as a school subject or a university major. As explained earlier, there are complex factors at work here, the most important of which seems to be the Islamic fundamentalist atmosphere, which is dominant throughout the country and which does its utmost to preserve local culture at the cost of hindering English education.

\section{References}

Abdollahzadeh, E., \& Baniasad, S. (2010). Ideologies in the imported English textbooks: EFL learners and teachers' awareness an attitude. Journal of English Language Teaching and Learning, 53(217), 1-17.

Bashir-Ali, K. (2006). Language learning and the definition of one's social, cultural, and racial identity. TESOL Quarterly, 40(3), 628-639. http://dx.doi.org/10.2307/40264549. 
Belz, J. A. (2002). Second language play as a representation of the multicompetent self in foreign language study. Journal of Language, Identity and Education, 1, 13-39. http://dx.doi.org/10.1207/ S15327701JLIE0101_3.

Block, D. (2002). Destabilized identities across language and cultural borders: Japanese and Taiwanese experiences. Hong Kong Journal of Applied Linguistics, 7(2), 1-19.

Block, D. (2007). The rise of identity in SLA research, post Firth and Wagner. The Modern Language Journal, 91(s1), 863-876. http://dx.doi.org/10.1111/j.1540-4781.2007.00674.x.

Block, D. (2008). Narrative, identity and interviews: A personal reflection on key constructs and analytical practices. In M. Solly, M. Conoscenti, \& S. Campagna (Eds.), Verbal/ visual narrative texts in higher education (pp. 25-52). Berlin, DE: Peter Lang.

Brown, H. D. (2005). Principles of language learning and teaching (5th ed.). White Plains, US: Pearson Longman.

Burck, C. (2011). Living in several languages: Language, gender and identities. European Journal of Women's Studies, 18(4), 361-378. http://dx.doi.org/10.1177/1350506811415196.

Byram, M. (2006, October). Languages and identities. Paper presented at the Intergovernmental Conference, Language Policy Division: Towards a framework for Europe. Strasbourg, France.

Caldas-Coulthard, C., \& Iedema, R. (Eds.). (2008). Identity trouble: Critical discourse and contested identities. New York, US: Palgrave Macmillan. http://doi.org/10.1057/9780230593329.

Chik, A., \& Benson, P. (2008). Frequent flyer: A narrative of overseas study in English. In: P. Kalaja, V. Menezes, \& A. M. Barcelos (Eds.), Narratives of learning and teaching EFL (pp. 155-170). London, UK: Palgrave.

Ellis, R. (2007). The study of second language acquisition. Oxford, UK: Oxford University Press.

Gao, Y. (2008). English learning and identity construction in the Chinese EFL context. In PacSLRF 2008 \& the Third National Symposium on SLA. Symposium conducted at the 6th meeting of the Pacific Second Language Research Forum (PacSLRF), Beijing.

Gao, Y. (2010). Models of L2 identity development revisited in the context of globalization. In X. Dai \& S. J. Kulich (Eds.), Identity and intercultural communication (I): Theoretical and contextual construction (pp. 239-259). Shanghai, CN: Shanghai Education Press.

Gao, Y., Li, Y., \& Li, W. (2002). EFL learning and self-identity construction: Three cases of Chinese college English majors. Asia Journal of English Language Teaching, 12, 95-119.

Gao, Y., Cheng, Y., Zhao, Y., \& Zhou, Y. (2005). Self-identity changes and English learning among Chinese undergraduates. World Englishes, 24(1), 39-51. http://doi.org/10.1111/j.08832919.2005.00386.x.

Gao, Y., Zhao, Y., Cheng, Y., \& Zhou, Y. (2007). Relationship between English learning motivation types and self-identity changes among Chinese students. TESOL Quarterly, 41(1), 133-155. http://doi.org/10.1002/j.1545-7249.2007.tb00043.x.

Gibson, K. (2004). English only court cases involving the U.S. workplace: The myths of language use and the homogenization of bilingual workers' identities. Second Language Studies, 22(2), $1-60$. 
Gu, M. M. (2009). Identities constructed in difference: English language learners in China. Journal of Pragmatics, 42(1), 139-152. http://dx.doi.org/10.1016/j.pragma.2009.06.006.

Gumperz, J. J., \& Cook-Gumperz, J. (1982). Introduction: Language and the communication of social identity. In J. J. Gumperz (Ed.), Language and social identity (pp. 1-21). Cambridge, UK: Cambridge University Press.

Hudson, R. A. (1996) Sociolinguistics (2nd ed.). Cambridge, UK: Cambridge University Press. http://dx.doi.org/10.1017/CBO9781139166843.

Ige, B. O. (2007). Impoliteness in context: Gender, impoliteness and construction of identities at a South African university (Unpublished doctoral dissertation). University of KwaZulu-Natal, Durban.

Jabur, Z. M. (2008). A qualitative study of Omani Muslim women's perceived experiences as writers in English as a second language (Unpublished doctoral dissertation). Indiana University of Pennsylvania, USA.

Joseph, E. J. (2004). Language and identity: National, ethnic, religious. London, UK: Palgrave Macmillan. http://doi.org/10.1057/9780230503427.

Kanno, Y. (2003). Negotiating bilingual and bicultural identities: Japanese returnees betwixt two worlds. Mahwah, US: Lawrence Erlbaum Associates.

Kim, L. S. (2003). Multiple identities in a multicultural world: A Malaysian perspective. Journal of Language, Identity, and Education, 2(3), 137-158. http://doi.org/10.1207/S15327701JLIE0203_1.

Kramsch, C. (1993). Context and culture in language teaching. Oxford, UK: Oxford University Press.

Le Page, R. B., \& Tabouret-Keller, A. (1985). Acts of identity: Creole-based approaches to language and ethnicity. Cambridge, UK: Cambridge University Press.

Mathews, G. (2000). Global culture/individual identity: Searching for a home in the cultural supermarket. London, UK: Routledge. http://doi.org/10.4324/9780203459348.

Menard-Warwick, J. (2005). Both a fiction and an existential fact: Theorizing identity in second language acquisition and literacy studies. Linguistics and Education, 16, 253-274. http://doi. org/10.1016/j.linged.2006.02.001.

Mezirow, J. (1991). Transformative dimensions of adult learning. San Francisco, US: Jossey-Bass.

Mills, J. (2001). Being bilingual: Perspectives of third generation Asian children on language, culture and identity. International Journal of Bilingual Education and Bilingualism, 4(6), 383-402. http://doi.org/10.1080/13670050108667739.

Miyahara, M. (2010). Researching identity and language learning: Taking a narrative approach. Language Research Bulletin, 25, 1-15.

Mokhtarnia, S. (2011). Language education in Iran: A dialogue between cultures or a clash of identities. Procedia: Social and Behavioral Sciences, 15, 1998-2002. http://doi.org/10.1016/j.sbspro.2011.04.042.

Norton, B. (1997). Language, identity, and the ownership of English. TESOL Quarterly, 31(3), 409429. http://doi.org/10.2307/3587831.

Norton, B. (2001). Non-participation, imagined communities, and language classroom. In M. P. Breen (Ed.), Learner contributions to language learning (pp. 159-171). Harlow, UK: Longman. 
Norton, B. (2006). Identity: Second language. In K. Brown (Ed.), Encyclopedia of language and linguistics (2nd ed., pp. 502-508). Oxford, UK: Elsevier. http://doi.org/10.1016/B0-08-0448542/00624-6.

Norton, B. (2008). Identity, language learning, and critical pedagogies. In J. Cenoz \& N. H. Hornberger (Eds.), Encyclopedia of language and education (2nd ed., Vol. 6, pp. 1811-1823). New York, US: Springer. http://doi.org/10.1007/978-0-387-30424-3_138.

Norton, B., \& Toohey, K. (2001). Changing perspectives on good language learners. TESOL Quarterly, 35(2), 307-322. http://doi.org/10.2307/3587650.

Pavlenko, A. (2001). "In the world of tradition, I was unimagined": Negotiation of identities in cross-cultural autobiographies. The International Journal of Bilingualism, 5(3), 317-344. http:// doi.org/10.1177/13670069010050030401.

Pavlenko, A. (2003). "I never knew I was a bilingual": Reimagining teacher identities in TESOL. Journal of Language, Identity, and Education, 2(4), 251-268. http://doi.org/10.1207/ S15327701JLIE0204_2.

Pavlenko, A. (2006). Bilingual selves. In A. Pavlenko (Ed.), Bilingual minds: Emotional experience, expression and representation (pp. 1-33). Cleveland, US: Multilingual Matters.

Pavlenko, A., \& Blackledge, A. (Eds.). (2003). Negotiation of identities in multilingual contexts. Clevedon, UK: Multilingual Matters.

Pishghadam, R., \& Sadeghi Ordoubody, M. (2011). Culture and identity change among Iranian EFL teachers. Ozean Journal of Social Sciences, 4(3), 147-162.

Riley, P. (2006). Self-expression and the negotiation of identity in a foreign language. International Journal of Applied Linguistics, 16(3), 295-318. http:// doi.org/10.1111/j.1473-4192.2006.00120.x.

Ryan, S. (2006). Language learning motivation within the context of globalization: An L2 self within an imagined global community. Critical Inquiry in Language Studies, 3(1), 23-45. http:// doi.org/10.1207/s15427595cils0301_2.

Shardakova, M., \& Pavlenko, A. (2004). Identity options in Russian textbooks. Journal of Language, Identity, and Education, 3(1), 25-46. http://doi.org/10.1207/s15327701jlie0301_2.

Skutnabb-Kangas, T. (2000). Linguistic genocide in education - Or worldwide diversity and Human Rights? Mahwah, US: Lawrence Erlbaum.

Sterling, P. (2000). Identity in language: An exploration into the social implications of linguistic variation. AGOR A Journal, 1(2), 1-17.

Taylor, C., \& Gibbs, G. R. (2010). How and what to code. Online QDA Web Site. Retrieved from http://onlineqda.hud.ac.uk/Intro_QDA/how_what_to_code.php.

Toohey, K. (2000). Learning English at school: Identity, social relations, and classroom practice. Clevedon, UK: Multilingual Matters.

Weedon, C. (1997). Feminist practice and poststructuralist theory (2nd ed.). Oxford, UK: Blackwell.

Wenger, E. (1998). Communities of practice: Learning, meaning, and identity. Cambridge, UK: Cambridge University Press. http://doi.org/10.1017/CBO9780511803932. 
Wu, H.-P. (2011). Exploring the relationship between EFL college students' multimodal literacy practices and identity on academic language use (Unpublished doctoral dissertation). The University of Texas at San Antonio, USA.

Zacharias, N. T. (2010). Acknowledging learner multiple identities in the EFL classroom. k@ta, 12(1), 26-41. http://doi.org/10.9744/kata.12.1.26-41.

\section{The Author}

Razieh Gholaminejad is a PhD candidate studying TEFL (teaching English as a foreign language) at the University of Shahid Beheshti in Tehran (Iran). Her research interests include identity and language acquisition, corpus analysis, and academic discourse analysis. 


\section{Appendix: Questions of the Open-Ended Questionnaire and Interview}

Please answer all of the questions below.

\section{Part one: Background questions}

1. Religion

2. Experience of living abroad

3. Mother tongue

\section{Part two: The main questions}

4. Do you think by learning English you have learned new beliefs, ideas, meanings, and more about other or certain culture/s during the period of learning English?

5. Do you feel a different person in a way when using English?

6. How is your experience affected and formed in using in English as a foreign language?

7. Do you think learning and/or using English has affected the way you think and perceive certain issues? If yes, please mention the issues.

8. Do you feel you have two identities (two personalities), one in English and one in Persian? If yes, how are these identities similar and/or different from each other? 